\title{
Role of Glycine N-Methyltransferase in the Regulation of T-Cell Responses in Experimental Autoimmune Encephalomyelitis
}

\author{
Chung-Hsien Li, ${ }^{1,2}$ Ming-Hong Lin, ${ }^{3}$ Shih-Han Chu, ${ }^{1,2}$ Pang-Hsien Tu, ${ }^{4}$ Cheng-Chieh Fang, ${ }^{1,2}$ \\ Chia-Hung Yen, ${ }^{2,5}$ Peir-In Liang, ${ }^{6}$ Jason C Huang, ${ }^{7}$ Yu-Chia Su, Huey-Kang Sytwu, and \\ Yi-Ming Arthur Chen , $^{2,10}$
}

${ }^{1}$ Institute of Microbiology and Immunology, National Yang-Ming University, Taipei, Taiwan; ${ }^{2}$ Center for Infectious Disease and Cancer Research (CICAR), Kaohsiung Medical University, Kaohsiung, Taiwan; ${ }^{3}$ Department and Graduate Institute of Microbiology and Immunology, National Defense Medical Center, Taipei, Taiwan; ${ }^{4}$ Institute of Biomedical Sciences, Academia Sinica, Taipei, Taiwan; ${ }^{5}$ Graduate Institute of Natural Products, College of Pharmacy, Kaohsiung Medical University, Kaohsiung, Taiwan; ${ }^{6}$ Department of Pathology, Kaohsiung Medical University Hospital, Kaohsiung Medical University, Kaohsiung, Taiwan; ${ }^{7}$ Department of Biotechnology and Laboratory Science in Medicine, National Yang-Ming University, Taipei, Taiwan; ${ }^{8}$ National Laboratory Animal Center, National Applied Research Laboratories; ${ }^{9}$ Institute of Biomedical Sciences, National Sun Yat-sen University, Kaohsiung, Taiwan; and ${ }^{10}$ Department of Microbiology and Immunology, Institute of Medical Research and Institute of Clinical Medicine, College of Medicine, Kaohsiung Medical University, Kaohsiung, Taiwan

\begin{abstract}
Glycine N-methyltransferase (GNMT) is known for its function as a tumor suppressor gene. Since $100 \%$ of female $\mathrm{Gnmt}^{-/-}$mice developed hepatocellular carcinoma, we hypothesized that $\mathrm{Gnmt}^{-/-}$mice may have defective immune surveillance. In this study, we examined the immune modulation of GNMT in T-cell responses using experimental autoimmune encephalomyelitis (EAE). The results showed that EAE severity was reduced significantly in $\mathrm{Gnmt}^{-/-}$mice. Pathological examination of the spinal cords revealed that $\mathrm{Gnmt}^{-1-}$ mice had significantly lower levels of mononuclear cell infiltration and demyelination than the wild-type mice. In addition, quantitative real-time PCR showed that expression levels of proinflammatory cytokines, including interferon (IFN)- $\gamma$ and interleukin (IL)-17A, were much lower in the spinal cord of $\mathrm{Gnmt}^{-/-}$than in that of wild-type mice. Accordingly, myelin oligodendrocyte glycoprotein (MOG)-specific T-cell proliferation and induction of T-helper (Th)1 and Th17 cells were markedly suppressed in $\mathrm{MOG}_{35-55}$-induced $\mathrm{Gnmt}^{-/-}$mice. Moreover, the number of regulatory T (Treg) cells was increased significantly in these mice. When the T-cell receptor was stimulated, the proliferative capacity and the activation status of mTOR-associated downstream signaling were decreased significantly in Gnmt ${ }^{-/-}$CD4 ${ }^{+}$T cells via an IL-2- and CD25-independent manner. Moreover, GNMT deficiency enhanced the differentiation of Treg cells without affecting the differentiation of Th1 and Th17 cells. Furthermore, the severity of EAE in mice adoptive transferred with GNMT-deficient CD4 ${ }^{+} \mathrm{T}$ cells was much milder than in those with wild-type CD4 ${ }^{+} \mathrm{T}$ cells. In summary, our findings suggest that GNMT is involved in the pathogenesis of EAE and plays a crucial role in the regulation of CD4 ${ }^{+}$T-cell functions.
\end{abstract}

Online address: http://www.molmed.org

doi: $10.2119 /$ molmed.2014.00133

\section{INTRODUCTION}

Glycine N-methyltransferase (GNMT, EC 2.1.1.20) regulates the ratio of $S$-adenosylmethionine (SAM) to

Address correspondence to Yi-Ming Arthur Chen, No. 100, Shih-Chuan Ist Rd, Kaohsiung City, Taiwan 80708.Phone: 886-7-31 17820; Fax: 886-7-3212062; E-mail: arthur@kmu.edu.tw. Submitted July 7, 2014; Accepted for publication December 12, 2014; Epub (www.molmed.org) ahead of print December 12, 2014.

The Feinstein Institute for Medical Research Empowering Imagination. Pioneering Discovery.
S-adenosylhomocysteine (SAH) and serves as a folate-binding protein $(1,2)$. GNMT binds environmental carcinogens and prevents the DNA adduct formation 
oped HCC (7-9). Therefore, GNMT is a tumor suppressor gene for HCC.

Since a high percentage of $\mathrm{Gnmt}^{-/-}$ mice developed HCC, we hypothesized that GNMT deficiency may affect the immune surveillance system. Accumulating evidence suggests that GNMT plays a critical role in the regulation of immune responses. Previously, we reported that compared with the wild-type mice, $\mathrm{Gnmt}^{-/-}$mice had significantly lower numbers of white blood cells, neutrophils and monocytes (10). In addition, cell numbers of lymphocytes, basophils and eosinophils were decreased slightly in knockout mice compared with wildtype mice (10). In Gnmt and apolipoprotein E double knockout mice, GNMT deficiency modulated the functions of macrophages and exacerbated the pathogenesis of hyperlipidemia, inflammation and atherosclerosis, indicating that GNMT regulates the inflammatory responses by modulating the function of macrophages (11). Moreover, GNMT deficiency increased the susceptibility to dextran sulfate sodium (DSS)-induced colitis in mice (12). Natural killer (NK) cells from $\mathrm{Gnmt}^{-/-}$mice were activated spontaneously, expressed more tumor necrosis factor (TNF)-related apoptosisinducing ligand (TRAIL) and had stronger cytotoxic activity, suggesting that they contributed to a proinflammatory environment in the liver (13). These lines of evidence indicate that GNMT is involved in the pathogenesis of inflammatory processes. However, whether GNMT regulates the functions of $\mathrm{CD}^{+}$ T-helper (Th) cell lineages is still unclear.

Multiple sclerosis (MS) is a chronic inflammatory, demyelinating, T-cellmediated autoimmune disease of the central nervous system (14). In addition to an immunological etiology, it has been reported that deficiency of SAM, a major methyl group, appears to be a pathogenic mechanism in various neurological disorders, including MS (15). Many of these diseases containing a myelination defect or demyelination were found to be associated with inborn error of metabolism, which affected the methyl transfer pathway $(16,17)$, suggesting that metabolic events also played a role in the pathogenesis of MS. Murine experimental autoimmune encephalomyelitis (EAE), a widely used animal model for human MS, provides a crucial tool for improving our understanding and treatment of multiple sclerosis (18). Th1 and Th17 cells are well documented to promote the progression of autoimmune encephalomyelitis (21). Our study aims to further investigate the modulatory role of GNMT in the regulation of T-cell functions during EAE pathogenesis.

\section{MATERIALS AND METHODS}

\section{Mice}

C57BL/ 6 mice were purchased from the National Laboratory Animal Center in Taipei, Taiwan. Gnmt ${ }^{-/}$mice in a C57BL/ 6 background were generated as described previously (10). B6.Rag $1^{-/-}$mice were originally acquired from The Jackson Laboratory (Bar Harbor, ME, USA). Eight- to 12-wk-old female mice were used for all experiments. All mice were housed in a specific pathogen-free facility in microisolator cages that contained sterilized food, autoclaved bedding and water. All animal protocols were reviewed and approved by the Institutional Animal Care and Use Committee of National Yang-Ming University.

\section{Induction of EAE}

To induce EAE, adult female mice ( $\mathrm{n}=$ 7-12/group) were immunized subcutaneously with $200 \mu \mathrm{g}$ of myelin oligodendrocyte glycoprotein $\left(\mathrm{MOG}_{35-55}\right)$ peptide (MEVGWYRSPFSRVVHLYRNGK, >95\% purity; Angene Biotech, Taiwan) emulsified in complete Freund's adjuvant containing $4 \mathrm{mg} / \mathrm{mL}$ Mycobacterium tuberculosis H37Ra (Difco, Detroit, MI, USA) in one flank on $\mathrm{d} 0$ and in the other on $\mathrm{d} 7$. Pertussis toxin (PTx; Sigma-Aldrich, St. Louis, MO, USA) (500 ng) was injected intraperitoneally on $\mathrm{d} 0$ and 2 postimmunization. Following the first immunization, the severity of EAE was monitored and scored in a blinded manner on a scale of 0 to 5 according to the following criteria: 0 , no clinical signs; 0.5 , partially limp tail; 1 , paralyzed tail; 2 , loss in coordinated movement, hind limb weakness; 2.5 , one hind limb paralyzed; 3 , both hind limbs paralyzed; 3.5 , hind limbs paralyzed, forelimbs weakness; 4 , forelimbs paralyzed; 5, moribund and death (22).

\section{Pathologic and Immunohistochemical (IHC) Examinations}

On d 17 postimmunization, mice $(n=4$ / group) were perfused with phosphatebuffered saline (PBS) transcardially. Then, their spinal cords were harvested and fixed in $4 \%$ formalin. The fixed tissues were embedded in paraffin wax. Five-micrometer sections were stained with hematoxylin and eosin (H\&E), CD45 or Luxol fast blue (LFB) for the analyses of inflammation and demyelination, respectively. Detailed procedures for IHC staining have been described previously (4). Rat anti-mouse CD45 (30-F11) antibody (BD Pharmingen [BD Biosciences, San Jose, CA, USA]) was used for staining. Slides were assessed in a blind fashion for inflammation and demyelination by the pathologist as follows (23). For inflammation: 0 , none; 1 , a few inflammatory cells; 2 , organization of perivascular infiltrates; and 3 , increasing severity of perivascular cuffing with extension into the adjacent tissue. For demyelination: 0 , none; 1 , rare foci; 2 , a few areas of demyelination; and 3 , large (confluent) areas of demyelination.

\section{Gene Expression Analysis by Using Real-time PCR}

On $\mathrm{d} 17$ postimmunization, the mice ( $n=4$ /group) were perfused with PBS transcardially before their spinal cords were removed and treated with TRIzol reagent (Invitrogen [Thermo Fisher Scientific, Waltham, MA, USA]). Tissues were homogenized with a tissue lyser (Qiagen, Valencia, CA, USA). The RNA was extracted with TRIzol reagent and was reverse transcribed into cDNA using a Super Script II Reverse Transcriptase Kit (Invitrogen [Thermo Fisher Scientific]). The PCR was performed on a thermal cycler system (Roche Diagnostics, 
Mannhein, Germany) using the LightCycler First Start DNA Master SYBR Green I system (Roche). The mRNA level was normalized using the $\beta$-actin mRNA level as the standard and expressed as fold changes compared with the WT mice.

\section{MOG-Specific T-Cell Proliferation}

The suspensions of mononuclear cells from pooled draining lymph nodes (LNs) were prepared on d 9 postimmunization ( $\mathrm{n}=3$ /group) and cultured in complete RPMI medium (RPMI 1640 containing heat-inacatived $10 \%$ fetal bovine serum, penicillin $(100 \mathrm{U} / \mathrm{mL})$, streptomycin $(100 \mu \mathrm{g} / \mathrm{mL})$, nonessential amino acids $(0.1 \mathrm{mmol} / \mathrm{L}), 10 \mathrm{mmol} / \mathrm{L}$ HEPES, $55 \mu \mathrm{mol} / \mathrm{L} \beta$-mercaptoethanol and $1 \mathrm{mmol} / \mathrm{L}$ sodium pyruvate) (Gibco [Thermo Fisher Scientific, Waltham, MA, USA]) in the absence or presence of various concentrations of $\mathrm{MOG}_{35-55}$ peptide. For proliferation, $\left[{ }^{3} \mathrm{H}\right]$-thymidine $(1 \mu \mathrm{Ci}$ / well; PerkinElmer, Shelton, CT, USA) was added at $24 \mathrm{~h}$, and the incorporated radioactivity was measured after $12 \mathrm{~h}$ using a PerkinElmer Wallac 1450 Micro $\beta$ Trilux Scintillation Counter (PerkinElmer). The amount of $\left[{ }^{3} \mathrm{H}\right]$-thymidine incorporation for each group was normalized to that of the unstimulated control, producing a ratio, referred to here as the proliferation index.

\section{Intracellular Cytokine Staining}

Mice were euthanized at d $9(n=3 /$ group), d 11 ( $\mathrm{n}=3 /$ group) and $d 18$ ( $\mathrm{n}=$ 3 /group) postimmunization. Single cell suspensions were prepared from draining LNs of mice. Cells were stimulated with PMA (20 ng/mL, Sigma) and ionomycin $(1 \mu \mathrm{g} / \mathrm{mL}$, Sigma) in the presence of monensin ( $4 \mu \mathrm{mol} / \mathrm{L}$, Sigma) for $4 \mathrm{~h}$. One million cells per reaction were stained with fluorochrome-conjugated antibodies specific for murine CD4 (RM4-5) (eBioscience, San Diego, CA, USA). Intracellular cellular cytokine staining was performed as described previously (24). Cells were stained with specific antibodies for murine interferon (IFN)- $\gamma$ (XMG1.2), interleukin (IL)-17A (TC11-18H10.1) and FoxP3 (FJK-16s)
(eBioscience). Cells were analyzed using a FACSCalibur flow cytometer (BD Biosciences) and Flow Jo software (Tree Star, Ashland, OR, USA)

\section{Isolation of Murine CD4 ${ }^{+} \mathrm{T}$ Cells}

Spleen and LNs were removed from 8- to 12-wk-old mice, pooled and homogenized through a filter. RBC were lysed using the red blood cell lysing buffer. $\mathrm{CD}^{+} \mathrm{T}$ cells were isolated by negative selection using Easy Sep Mouse CD4 ${ }^{+} \mathrm{T}$ Cell Enrichment Kit (Stem Cell Technologies, Vancouver, BC, Canada) or using $\mathrm{CD}^{+} \mathrm{T}$ Cell Isolation Kit II (Miltenyi Biotec, Bergisch Gladbach, Germany).

\section{Enzyme-Linked Immunosorbent Assay (ELISA)}

The $\mathrm{CD}^{+} \mathrm{T}$ cells were purified as described above and stimulated with anti-CD3/CD28 (1 $\mu \mathrm{g} / \mathrm{mL})$ for $48 \mathrm{~h}$. The supernatants were collected after stimulation and different quantitative ELISAs were performed using paired monoclonal antibodies (mAbs) as recommended by the manufacturer (R\&D Systems, Minneapolis, MN, USA).

\section{Cell Stimulation and Western Blot Analysis}

The $\mathrm{CD}^{+} \mathrm{T}$ cells were purified from 8- to 12-wk-old mice and stimulated with anti-CD3ع (145-2C11, eBioscience) and anti-CD28 (37.51, eBioscience) Abs. After stimulation, cells were immediately harvested with radioimmunoprecipitation assay (RIPA) lysis buffer containing protease and phosphatase inhibitors. Cell lysates were analyzed by using 10\% sodium dodecyl sulfate-polyacrylamide gel electrophoresis (SDS-PAGE) and transferred to nitrocellulose membrane according to the protocol reported previously (8). Densitometry was performed using Dolphin View Band Tool (Wealtec Corp., Sparks, NV, USA). The membranes were reactive to the following Abs: phospho-T389 S6K1 (9205), phospho-S2448 mTOR (2971), phosphoT37/T46 4E-BP1 (9459) (Cell Signaling Technology, Beverly, MA, USA), GRAIL
(Imgenex [Novus Biologicals LLC, Littleton, CO, USA]) and $\beta$-actin (Sigma).

\section{Analysis of the T-Cell Differentiation}

The $\mathrm{CD} 4{ }^{+} \mathrm{CD} 25^{-} \mathrm{T}$ cells were purified from pooled spleen and draining LNs of 8 - to 12 -wk-old mice ( $\mathrm{n}=5-9 /$ group) and stimulated with anti-CD3e $(1 \mu \mathrm{g} / \mathrm{mL})$ and anti-CD28 $(1 \mu \mathrm{g} / \mathrm{mL}) \mathrm{mAbs}$ under Th1 (IL-12, 10 ng/mL; anti-IL-4 (11B11), $10 \mu \mathrm{g} / \mathrm{mL}$ ), Th17 (IL-6, $10 \mathrm{ng} / \mathrm{mL}$; TGF- $\beta, 1 \mathrm{ng} / \mathrm{mL}$; anti-IL-4, $10 \mu \mathrm{g} / \mathrm{mL}$; anti-IFN- $\gamma$ (XMG1.2), $10 \mu \mathrm{g} / \mathrm{mL})$ or induced regulatory $\mathrm{T}$-cell (iTreg) condition (TGF- $\beta, 5 \mathrm{ng} / \mathrm{mL}$; IL-2, $10 \mathrm{ng} / \mathrm{mL}$; antiIL-4, $10 \mu \mathrm{g} / \mathrm{mL}$; anti-IFN- $\gamma, 10 \mu \mathrm{g} / \mathrm{mL}$ ) for $3 \mathrm{~d}$. The cytokines were purchased from eBioscience. The neutralizing antibodies were purchased from BioLegend (San Diego, CA, USA). Intracellular cytokine staining was performed as described above.

\section{Adoptive Transfer EAE}

Female 8- to 12-wk-old mice ( $\mathrm{n}=5$ / group) were EAE induced as described above. Draining LNs and spleen cells were harvested $9 \mathrm{~d}$ later and cultured in complete RPMI medium containing $\mathrm{MOG}_{35-55}(50 \mu \mathrm{g} / \mathrm{mL})$ for $4 \mathrm{~d}$. After harvesting, $\mathrm{CD} 4^{+} \mathrm{T}$ cells were purified by negative selection using Easy Sep Mouse $\mathrm{CD}^{+}{ }^{+} \mathrm{T}$ Cell Enrichment Kit (Stem Cell Technologies). Viable CD4 ${ }^{+}$T cells $(6 \times$ $10^{6}$; purity $>95 \%$ ) were then transferred intraperitoneally into female C57BL/ 6 mice ( $n=3-4 /$ group). Mice were given 500 ng of PTx intraperitoneally on d 0 and 2 after transfer.

For adoptive transfer to $\operatorname{Rag} 1^{-/}$recipients, the $\mathrm{CD}^{+} \mathrm{T}$ cells were isolated from 8- to 12-wk-old wild-type and $\mathrm{Gnmt}^{-/}$ mice ( $n=5$ /group) as described above. $\mathrm{CD}^{+} \mathrm{T}$ cells $\left(7 \times 10^{6}\right)$ were injected in the tail vein of adult female $R a g 1^{-/}$mice ( $\mathrm{n}=3-4$ /group). After $24 \mathrm{~h}, \mathrm{Rag}^{-/-}$recipients were induced EAE as described above.

\section{Statistics}

The $\chi^{2}$ test was used for comparison of incidence of EAE. The unpaired twotailed Student $t$ test was applied for sta- 


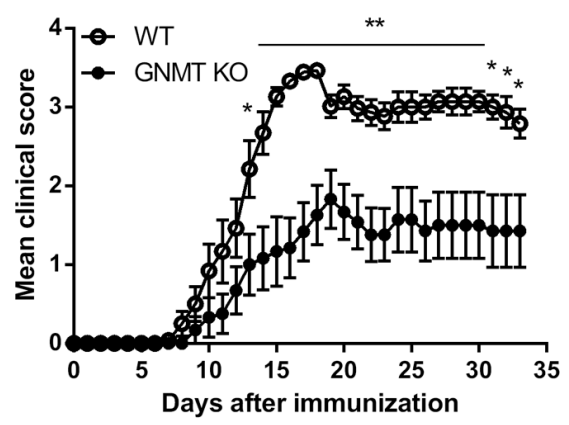

B

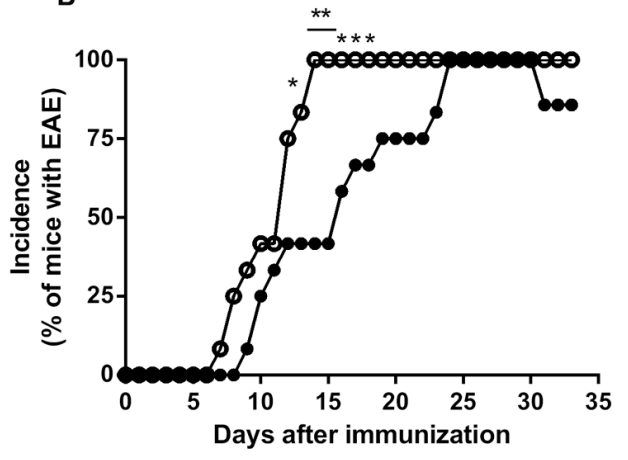

Figure 1. GNMT deficiency impaired development of EAE. 8- to 12-wk-old female wild-type, $\mathrm{Gnmt}^{-/-}$mice were induced with EAE by immunization with $200 \mu \mathrm{g}$ of $\mathrm{MOG}_{35-55}$ emulsified in CFA and co-injection with pertussis toxin. (A) Mean clinical scores of diseased mice. (B) Incidence of EAE. Pooled data of two independent experiments including 7-12 mice per group are presented. Data are presented as mean clinical scores \pm SEM. Statistics were calculated by the Student $t$ test $(A)$ and the $\chi^{2}$ test (B), respectively. ${ }^{*} p<0.05$; ${ }^{* *} p<0.01$.

tistical analysis of other experiments in this study. The differences were considered to be significant when $p<0.05$. ${ }^{*} p<$ $0.05,{ }^{* *} p<0.01$.

All supplementary materials are available online at www.molmed.org.

\section{RESULTS}

\section{GNMT Is Dispensable for T-Cell Activation and Homeostasis in a Steady-State Manner}

GNMT was reported to play a critical role in innate immunity $(11,13)$. However, the role of GNMT in adaptive immunity remains unknown. To determine whether GNMT deficiency modulated the T-cell development, we analyzed the percentages of lymphocyte populations $\left(\mathrm{CD}^{+}, \mathrm{CD}^{+}\right.$, and $\left.\mathrm{CD} 19^{+}\right)$in the spleen of $\mathrm{Gnmt}^{-/-}$mice. Total numbers of cells in spleen were comparable between $\mathrm{Gnmt}^{-/-}$ and wild-type mice (data not shown). $\mathrm{Gnmt}^{-/}$mice had a slightly higher percentage of $\mathrm{CD} 4^{+}$cells but a slightly lower percentage of $\mathrm{CD} 19^{+}$cells than wild-type mice, respectively (Supplementary Figures $1 \mathrm{~A}, \mathrm{~B})$. Nevertheless, the percentages of $\mathrm{CD}^{+}$cells in the spleen were similar between the $\mathrm{Gnmt}^{-/-}$and wild-type mice (see Supplementary Figures 1A, B). Moreover, the percentages of $\mathrm{CD}^{+} \mathrm{FoxP}^{+}$ regulatory $\mathrm{T}$ (Treg) cells were equal between wild-type and $\mathrm{Gnmt}^{-/}$mice (Supplementary Figures 1C, D). These results suggested that GNMT deletion had a mild impact on lymphocytic populations of spleen. Furthermore, to examine whether GNMT ablation influenced T-cell activation status, we compared the activation marker CD69 in either $\mathrm{CD}^{+}$ or $\mathrm{CD}^{+} \mathrm{T}$ cells. Our results indicated that the percentages of $\mathrm{CD} 69^{+} \mathrm{CD} 4^{+}$or $\mathrm{CD} 9^{+} \mathrm{CD}^{+}$were similar between $\mathrm{Gnmt}^{-/-}$and wild-type mice, excluding the role of GNMT in T-cell activation (Supplementary Figures 1E, F). To further investigate whether GNMT deficiency affected T-cell homeostasis, we analyzed effector $\left(C D 44{ }^{\text {hi }} \mathrm{CD} 62^{\text {lo }}\right)$ and memory (CD44 ${ }^{\text {hi }}$ CD62 $L^{\text {hi }}$ ) populations in either $\mathrm{CD}^{+}$or $\mathrm{CD}^{+} \mathrm{T}$ cells in the spleen. Our results also revealed that wild-type and $\mathrm{Gnmt}^{-/}$mice had equal frequencies of effector and memory populations in $\mathrm{CD}^{+}$or $\mathrm{CD}^{+} \mathrm{T}$ cells of the spleen (Supplementary Figures 1G, H). These results suggested that GNMT deficiency had a dispensable effect in the activation and homeostasis of steadystate $\mathrm{T}$ cells in peripheral lymphoid organs.

\section{GNMT Ablation Ameliorates the Disease Severity of EAE}

To investigate whether GNMT played a modulatory role in autoimmune disease, we used $\mathrm{MOG}_{35-55}$-induced EAE model to test the clinical manifestations in $\mathrm{Gnmt}^{-/}$mice. Our results showed that the development of $\mathrm{MOG}_{35-55}$-induced EAE was markedly attenuated in $\mathrm{Gnmt}^{-/}$ mice, which were characterized by a significantly delayed onset of disease (14.3 \pm $1.46 \mathrm{~d}$ ) and a decreased disease severity (mean maximal clinical score, $2.17 \pm 0.39$ ) in comparison with wild-type mice, suggesting a protective role of GNMT deficiency in EAE (Figure 1A and Table 1). In addition, we further compared the incidence of EAE between $\mathrm{Gnmt}^{-/}$and wildtype mice. Our results revealed that the kinetics of EAE progression was slightly attenuated in $\mathrm{Gnmt}^{-/}$mice compared with wild-type mice (Figure 1B). Moreover, wild-type mice showed $100 \%$ incidence of EAE at d 14 postimmunization while $\mathrm{Gnmt}^{-/-}$mice reached it at d 24 postimmunization (see Figure 1B). However, the patterns of change in body weight were similar between MOG-immunized wild-type and $\mathrm{Gnmt}^{-/-}$mice (Supplementary Figure 2). Collectively, these results demonstrated that GNMT deficiency significantly impaired the disease severity and the progressive kinetics of EAE in

Table 1. Clinical features of $\mathrm{MOG}_{35-55}$ peptide-induced EAE in WT and GNMT KO mice.

\begin{tabular}{lcccc}
\hline Type & $\begin{array}{c}\text { Mean day } \\
\text { of onset } \\
\text { (Mean } \pm \text { SEM) }\end{array}$ & $\begin{array}{c}\text { Mean maximal } \\
\text { clinical score } \\
\text { (Mean } \pm \text { SEM) }\end{array}$ & $\begin{array}{c}\text { Mean duration of } \\
\text { paralysis (score } \geq 2.5) \\
\text { (Mean } \pm \text { SEM) }\end{array}$ & $\begin{array}{c}\text { Mortality } \\
(\%)\end{array}$ \\
\hline WT & $10.92 \pm 0.7$ & 3.5 & $15.67 \pm 1.81$ & 0 \\
GNMT KO & $14.3 \pm 1.46^{\mathrm{a}}$ & $2.17 \pm 0.39^{\mathrm{b}}$ & $6.42 \pm 2.6^{\mathrm{b}}$ & 0 \\
\hline
\end{tabular}

${ }^{a} p<0.05$, determined by unpaired two-tailed Student $t$ test.

${ }^{b} p<0.01$, determined by unpaired two-tailed Student $t$ test. 
mice, suggesting a pathogenic role of GNMT in autoimmune encephalomyelitis.

\section{GNMT Deficiency Reduces Inflammation and Demyelination of the CNS}

To confirm whether GNMT deletion decreased inflammation and demyelination in inflamed CNS, we used immunohistochemical analysis to further compare leukocyte infiltration and demyelination of inflamed CNS between MOGimmunized $\mathrm{Gnmt}^{-/-}$and wild-type mice. Pathological examination of the spinal cords harvested from $17 \mathrm{~d}$ immunized wild-type (average score, $3.23 \pm 0.12$ ) and $\mathrm{Gnmt}^{-/-}$mice (average score, $1 \pm 0.7$ ) revealed significant differences between these two groups. Degeneration of white matter characterized by vacuolar formation along with extensive infiltration of inflammatory mononuclear cells was seen consistently in spinal cords of wildtype mice. In contrast, degeneration and inflammation was very mild in $\mathrm{Gnmt}^{-/}$ mice (Figure 2A-F, S). Consistently, IHC staining of the common leukocyte marker CD45 showed abundant inflammatory infiltrates in the spinal cords of the wild-type mice, but few or no leukocytes were detected in the Gnmt $t^{-/-}$mice (Figures 2G-L, S).

To assess the degree of demyelination, we examined the integrity of myelin sheaths by Luxol fast blue staining. As shown in Figures 2M-R and S, the MOGimmunized wild-type mice showed multiple areas of pallor, corresponding to the areas with vacuolar degeneration, in the white matter of the spinal cords. In contrast, the white matter of the spinal cords of $\mathrm{Gnmt}^{-/-}$mice was evenly stained throughout, indicating very mild or no demyelination. The pathological findings of the spinal cord of the wild-type and $\mathrm{Gnmt}^{-/-}$mice correlated very well with the clinical observations.

\section{GNMT Deficiency Downregulates Proinflammatory Cytokines in Inflamed CNS}

To investigate whether GNMT deficiency dampened the production of in-
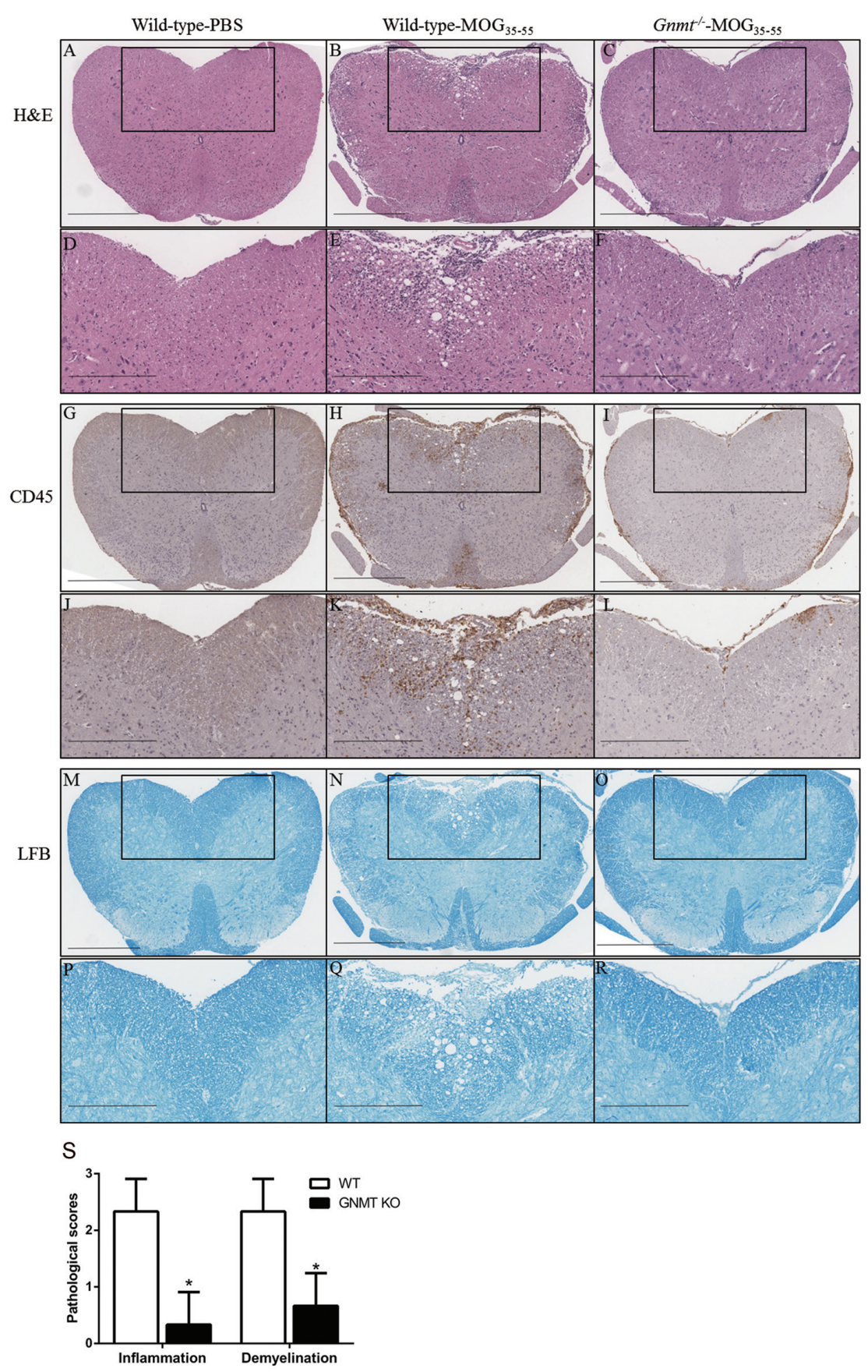

Figure 2. Histopathologic findings of spinal cords of the wild-type and $\mathrm{Gnmt}^{-/-}$mice $17 \mathrm{~d}$ after immunization with $\mathrm{MOG}_{35-55}$. (A-F) H\&E sections; (G-L) sections stained with anti-CD45 antibody; (M-R), sections stained with Luxol fast blue (LFB). The micrographs of second, fourth and sixth row were the amplified images of the boxed areas in the first, third and fifth rows, respectively. As shown, the wild-type $\mathrm{MOG}_{35-55}$ mice developed white matter damage with vacuoles on $\mathrm{H} \& \mathrm{E}$ sections $(\mathrm{B}, \mathrm{E})$ with $\mathrm{CD}-45$ positive inflammatory infiltrates $(\mathrm{H}, \mathrm{K})$ and patchy pallor on LFB stain $(\mathrm{N}, \mathrm{Q})$, but the $\mathrm{Gnmt}^{-/-} \mathrm{MOG}_{35-55}$ showed scant or no damage in the corresponding areas. (S) Mean pathological scores of inflammation and demyelination \pm SD are shown. Histology was performed in four different mice for each group, and representative images are shown. Scale bars in A-C, G-I, M-O: $500 \mu \mathrm{m}$; scale bars in D-F, J-L, P-R: $300 \mu \mathrm{m}$. Statistics were calculated by the Student $t$ test. ${ }^{*} P<0.05$. 
A
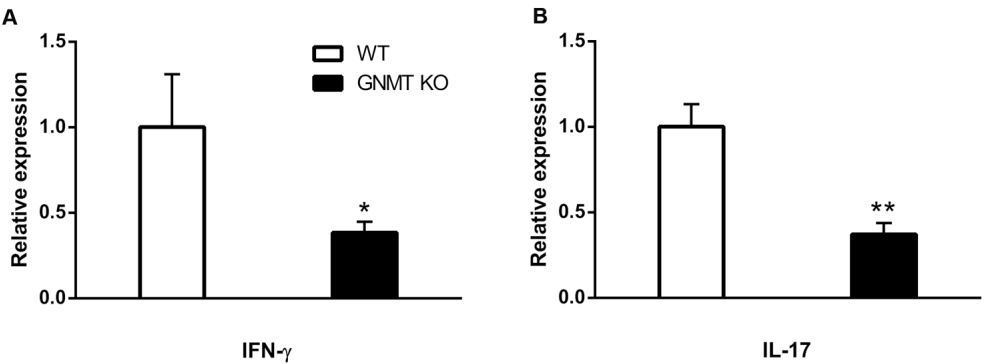

C

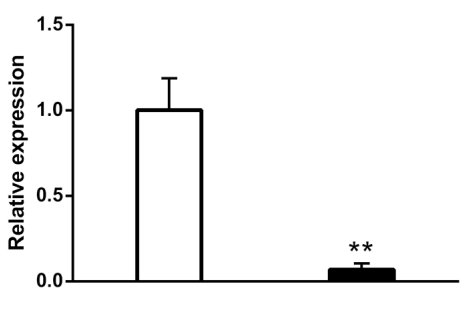

TNF- $\alpha$

E

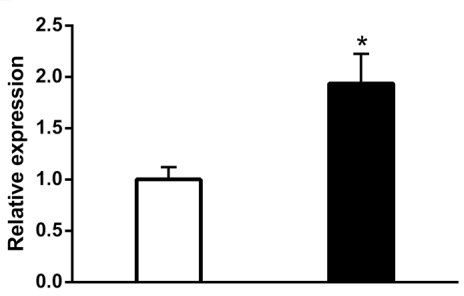

IL-10
D

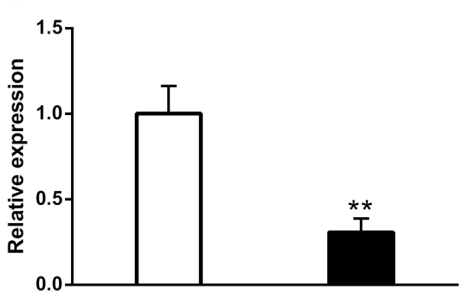

IL-6

3. Proinflammatory cytokine gene expression of inflamed CNS were reduced in $\mathrm{Gnmt}^{-/-}$mice. RNA was extracted from spinal cord of immunized wild-type and $\mathrm{Gnmt}^{-/-}$ mice. The expressions of mRNA were analyzed by q-PCR. The mRNA level was normalized to the $\beta$-actin mRNA level and subsequently expressed as fold changes relative to wildtype (WT) mice. All data are presented as mean \pm SEM from four mice in each group. Statistics were calculated by the Student $t$ test. ${ }^{*} p<0.05 ;{ }^{* *} p<0.01$.

flammatory cytokines, we analyzed the mRNA levels of inflammatory cytokines in the spinal cord of $17 \mathrm{~d}$ immunized mice. Our results indicated that the spinal cord of $\mathrm{Gnmt}^{-/-}$mice (average score, $1.8 \pm 0.48$ ) had significantly lower mRNA levels of proinflammatory cytokines, including IFN- $\gamma$, IL-17A, TNF- $\alpha$ and IL-6, than that of wild-type mice (average score, $2.9 \pm 0.29$ ) (Figures 3A-D), which is consistent with an attenuation in EAE severity in $\mathrm{Gnmt}^{-/-}$mice. Moreover, we also compared the mRNA level of IL-10, an immunosuppressive cytokine, in the spinal cord between these two groups. Our results revealed that the expression level of IL-10 mRNA was increased significantly in the spinal cord of $\mathrm{Gnmt}^{-/-}$mice compared with that of wild-type mice (Figure 3E). To further determine whether EAE induction affected the expression of GNMT, we analyzed the mRNA expression of GNMT in spinal cord of mice with $\mathrm{MOG}_{35-55^{-}}$ immunization. In comparison with the PBS control group, mRNA expression of GNMT was increased slightly in the spinal cord of MOG-immunized wildtype mice (Supplementary Figure 3). Collectively, these results indicated that GNMT deficiency inhibited inflammatory cytokines IFN- $\gamma$, IL-17A, TNF- $\alpha$ and IL-6; and in contrast, it promoted the immunosuppressive cytokine IL-10 in the inflamed CNS of $\mathrm{Gnmt}^{-/}$mice, suggesting a differential modulatory effect of
GNMT in the expression levels of these cytokines.

\section{Induction of MOG-Specific T cells Is Suppressed in $\mathrm{Gnmt}^{-/-}$Mice}

To determine whether GNMT deficiency impaired the encephalitogenic T-cell functions, we examined the $\mathrm{MOG}_{35-55}$ peptide-specific responses of lymphocytes from draining LNs. We cultured cells harvested from the draining LNs at $d 9$ postimmunization in the presence of various doses of $\mathrm{MOG}_{35-55}$ peptide and measured the proliferative responses. Our results indicated that the proliferative activity of lymphocytes from $\mathrm{Gnmt}^{-/-}$mice was decreased significantly in the presence of stimulation with various concentrations of MOG antigen $(10,20$ and $50 \mu \mathrm{g} / \mathrm{mL})$ compared with those of wild-type mice (Figure $4 \mathrm{~A}$ ), supporting an amelioration of EAE in $\mathrm{Gnmt}^{-/-}$mice. These results suggested that GNMT deficiency significantly decreased the proliferative response of $\mathrm{T}$ cells in an antigen-specific stimulation.

Th1 and Th17 are critical players in the pathogenesis of autoimmune encephalomyelitis (25). To further investigate the modulatory effect of GNMT deficiency on Th1 and Th17 cells in mice with EAE induction, we analyzed the percentages of Th1 and Th17 cells in $\mathrm{MOG}_{35-55^{-}}$ immunized $\mathrm{Gnmt}^{-/-}$mice (d 9 postimmunization). In line with the results of IFN- $\gamma$ and IL-17A mRNA levels in inflamed CNS, both the percentages of Th1 cells and Th17 cells were reduced significantly in MOG-immunized Gnmt ${ }^{-/}$mice when compared with those in wild-type mice (Figures 4B, C). Similarly, decreases in proliferative responses and cytokine production of IFN- $\gamma$ and IL-17A also were observed in $\mathrm{Gnmt}^{-/-}$mice compared with wild-type mice at d 23 after EAE induction (Supplementary Figures 4A-C). Furthermore, these results suggested that GNMT deficiency suppressed proliferative responses of MOG-specific T cells and induction of Th1 and Th17 cells, further supporting a protective role of GNMT deficiency in EAE. 
A

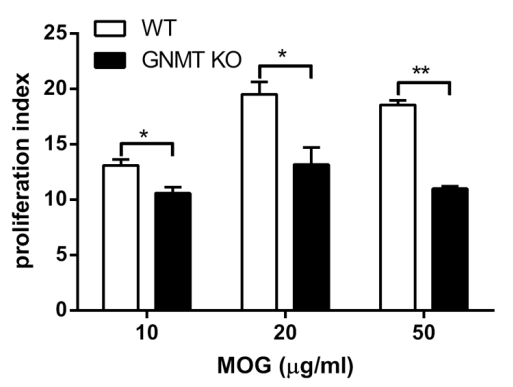

B

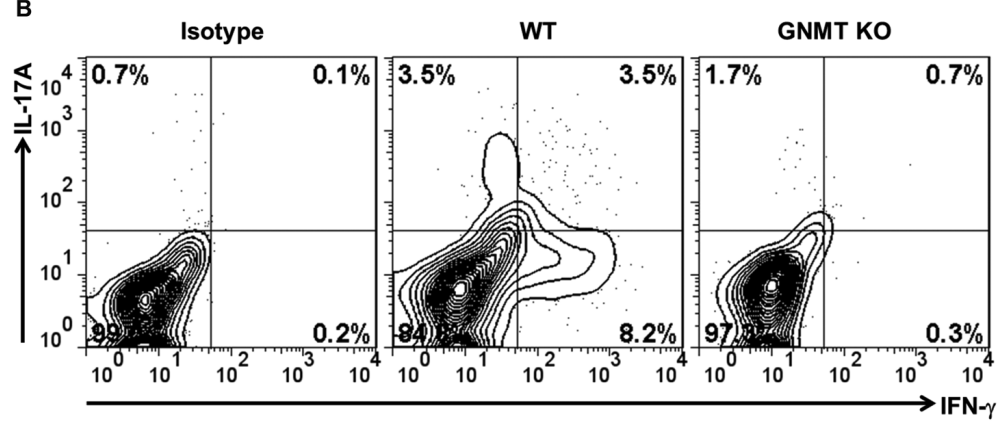

C
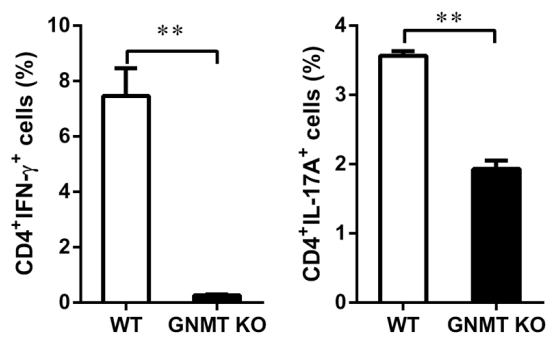

Figure 4. GNMT deficiency suppressed MOG-specific T-cell responses in peripheral lymphoid tissue. (A) The recovered lymphocytes from draining LNs of 9-d-postimmunized mice were restimulated with various concentrations of $\mathrm{MOG}_{35-55}$ peptide for $24 \mathrm{~h}$. The proliferative response was determined by $\left({ }^{3} \mathrm{H}\right)$ thymidine incorporation as described in Materials and Methods. (B and C) Lymphocytes were recovered from draining LNs of 9-d-postimmunized mice and stimulated with PMA and ionomycin in the presence of monensin. The percentages of Th1 and Th17-producing CD4 ${ }^{+} \mathrm{T}$ cells were analyzed by flow cytometry. Representative flow cytometric analysis (B) and the average percentages of $\mathrm{CD} 4^{+} \mathrm{IFN}-\gamma^{+}$and $\mathrm{CD} 4^{+}$

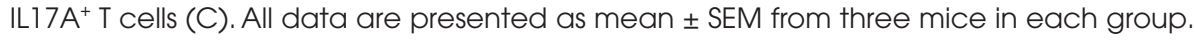
Statistics were calculated by the Student $t$ test. ${ }^{*} p<0.05$; ${ }^{* *} p<0.01$.

\section{Loss-of-Function of GNMT Attenuates TCR-Stimulated T-Cell Proliferation via the mTOR Signaling Pathway}

Given that EAE is a CD4 ${ }^{+}$T-cellmediated inflammatory demyelinating disease of the CNS (26), we further investigated the modulatory effect of GNMT deficiency in the proliferation of $\mathrm{CD}^{+} \mathrm{T}$ cells. Our results showed that the proliferative capacity of $\mathrm{CD} 4^{+} \mathrm{T}$ cells was significantly lower in $\mathrm{Gnmt}^{-/-}$mice than in wild-type mice at both time points (36 and $60 \mathrm{~h}$ after stimulation) (Figure 5A). These data suggested that GNMT promoted the proliferative activity of $\mathrm{CD} 4^{+}$ T cells.

It is well demonstrated that TCR/CD3 engagement and CD28 costimulation in- crease the expression level of IL-2R $\alpha$ (CD25) and the amount of secreted IL-2 in $\mathrm{T}$ cells (27-29). We next determined whether GNMT deficiency affected the amount of IL-2 production in the supernatant of cultured $\mathrm{CD} 4^{+} \mathrm{T}$ cells and the mRNA levels of IL-2 and CD25 in those $\mathrm{T}$ cells. Our results indicated that the amount of IL-2 production was increased equally in the culture supernatant of GNMT-deficient CD4 ${ }^{+} \mathrm{T}$ cells compared with that of wild-type T cells in response to the stimulation of antiCD3/CD28 (Figure 5B). Moreover, we also found that both wild-type and GNMT-deficient CD4 ${ }^{+} \mathrm{T}$ cells had similarly increased expression of IL-2 and CD25 in response to anti-CD3/CD28 stimulation (Figures 5C, D). Therefore, these results suggested that the deficiency of GNMT strikingly decreased $\mathrm{CD}^{+} \mathrm{T}$-cell proliferation in an IL-2- and CD25-independent manner.

Since Th1 and Th17 cells played important roles in the development and pathogenic processes of EAE $(19,20)$, we investigated whether GNMT deficiency influenced cytokine production of Th1 (IFN- $\gamma$ ) and Th17 (IL-17A) cells in antiCD3/CD28-stimulated CD4 ${ }^{+} \mathrm{T}$ cells. Our results revealed that production of both IFN- $\gamma$ and IL-17A was reduced significantly in the supernatant of cultured GNMT-deficient CD4 ${ }^{+} \mathrm{T}$ cells compared with wild-type T cells (Figures 5E, F). Collectively, these results suggested that GNMT deficiency impaired TCR stimulation-induced T-cell proliferation and dampened Th1-specific IFN- $\gamma$ and Th17specific IL-17A production.

Previous studies have shown that mTOR controls naïve CD4 ${ }^{+}$T-cell proliferation by regulating the protein expression of gene related to anergy in lymphocyte (GRAIL) (30). Previously we found that GNMT regulated the mTOR signaling pathway by interacting with an $\mathrm{mTOR}$ inhibitory protein-DEPTOR in HCC cells (5). To investigate whether GNMT deficiency affected the proliferative capacity of $\mathrm{CD} 4^{+} \mathrm{T}$ cells through the mTOR signaling pathway, we first examined TCR-mediated phosphorylation 
A

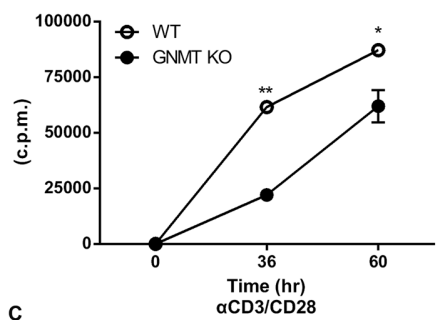

C

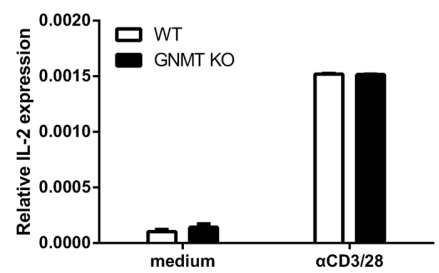

$\mathrm{E}$
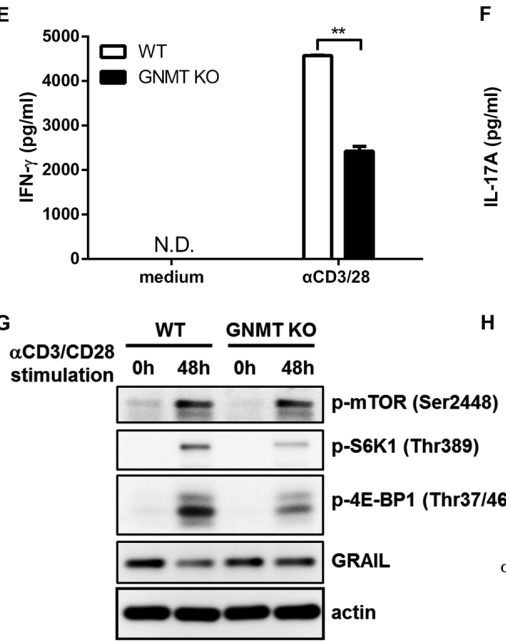

Figure 5. Attenuation of TCR-mediated responses and mTOR signaling transduction in GNMT-deficient CD4 ${ }^{+} \mathrm{T}$ cells. (A) Attenuation of TCR-mediated cell proliferation in $\mathrm{Gnmt}^{-/-}$ $\mathrm{CD}^{+}$cells. The purified $\mathrm{CD} 4^{+} \mathrm{T}$ cells isolated from $\mathrm{Gnmt}^{-/-}$mice and wild-type mice were stimulated with anti-CD3/CD28 $(1 \mu \mathrm{g} / \mathrm{mL})$. For proliferation, the $\left({ }^{3} \mathrm{H}\right)$ thymidine was pulsed at $24 \mathrm{~h}$ and $48 \mathrm{~h}$ after stimulation, and the incorporated radioactivity was measured after $12 \mathrm{~h}$ as described in Materials and Methods. Data are representative of two independent experiments, presented as the mean \pm SD. (B) TCR-induced IL-2 cytokine production was not affected by GNMT deficiency. The purified $C D 4^{+}$T cells were stimulated with anti-CD3/CD28 $(1 \mu \mathrm{g} / \mathrm{mL}$ ) for $48 \mathrm{~h}$. The supernatants were harvested and measured for IL-2 concentrations by ELISA. Data are representative of two independent experiments, presented as the mean \pm SD. (C,D) GNMT deficiency did not affect TCR-induced IL-2 and IL-2R $\alpha$ (CD25) mRNA expression. The purified CD4 ${ }^{+}$T cells were stimulated with anti-CD3/CD28 $(1 \mu \mathrm{g} / \mathrm{mL})$ for $24 \mathrm{~h}$ and the expression of IL-2 and CD25 were analyzed by q-PCR. Data are representative of two independent experiments, presented as the mean $\pm \mathrm{SD}$. (E and F) Attenuation of TCR-induced IFN- $\gamma$ and IL-17A production in $\mathrm{Gnmt}^{-/-} \mathrm{CD}^{+} \mathrm{T}$ cells. The purified CD4 T cells were stimulated with anti-CD3/CD28 $(1 \mu \mathrm{g} / \mathrm{mL})$ for $48 \mathrm{~h}$. The supernatants were collected and measured for IFN- $\gamma$ and IL-17A concentrations by ELISA. Data are representative of two independent experiments, presented as the mean \pm SD. (G) The purified CD4 ${ }^{+}$ T cells from $\mathrm{Gnmt}^{-/-}$mice or wild-type mice were stimulated with anti-CD3 and anti-CD28 $(1 \mu \mathrm{g} / \mathrm{mL})$ for $48 \mathrm{~h}$. The cell extracts were analyzed by SDS-PAGE and Western blotting with the indicated antibodies. $(H)$ Average densitometric quantification of immunoblots of GRAIL. Data are representative of at least three experiments. Statistics were calculated by the Student $\dagger$ test. ${ }^{*} p<0.05 ;{ }^{* *} p<0.01$. N.D., nondetermined. status of mTOR and its downstream effectors, S6 Kinase 1 (S6K1) and eIF-4Ebinding protein 1 (4E-BP1) $(31,32)$ in activated $\mathrm{CD}^{+} \mathrm{T}$ cells. Our results indicated that the TCR stimulation-induced phosphorylation status of mTOR kinase at Ser2448 was equally increased in both wild-type and $\mathrm{Gnmt}^{-/-} \mathrm{CD}^{+} \mathrm{T}$ cells (Figure 5G), suggesting a dispensable role of GNMT in this phosphorylation site of mTOR kinase. In contrast, the phosphorylation status of S6K1 at Thr389 and 4E-BP1 at Thr37/46 were suppressed remarkably in GNMTdeficient $\mathrm{CD}^{+} \mathrm{T}$ cells compared with wild-type $\mathrm{CD} 4^{+} \mathrm{T}$ cells (see Figure $5 \mathrm{G}$ ), indicating that GNMT deficiency critically modulated TCR stimulation-based phosphorylation status of mTOR downstream signaling, including S6K1 and 4E-BP1. Since activation of the mTOR signaling pathway promoted the proliferation of naïve $\mathrm{CD} 4^{+} \mathrm{T}$ cell by downregulating GRAIL expression (30), we examined whether GNMT deficiency regulated the level of GRAIL expression in activated $\mathrm{CD} 4^{+} \mathrm{T}$ cells. Our results indicated that, in the presence of anti-CD3/CD28 stimulation, GRAIL expression was reduced significantly in activated $\mathrm{CD}^{+} \mathrm{T}$ cells compared with steady-state $\mathrm{T}$ cells of wild-type mice (Figures 5G, H). Nevertheless, the expression level of GRAIL was only slightly decreased in activated $\mathrm{CD} 4^{+} \mathrm{T}$ cells compared with steady-state $\mathrm{T}$ cells from $\mathrm{Gnmt}^{-/-}$mice (see Figures 5G, H), which is consistent with an attenuation of T-cell proliferation in GNMT-deficient mice. Collectively, these data suggested that GNMT deficiency attenuated TCR stimulation-activated $\mathrm{CD} 4^{+} \mathrm{T}$-cell proliferation at least partly via the $\mathrm{mTOR}$ signaling pathway.

\section{GNMT Deficiency Enhances the Differentiation of Treg Cells In Vitro}

Our results showed that GNMT deficiency significantly decreased the TCR stimulation-induced responses of $\mathrm{CD}^{+}$ $\mathrm{T}$ cells, including proliferation and cytokine production (Figure 5). However, the modulatory role of GNMT in T-cell 
differentiation is still unknown. We further investigated whether GNMT deletion affected the differentiation of Th1 and Th17 cells. The CD4 ${ }^{+} \mathrm{CD} 25^{-} \mathrm{T}$ cells were purified from pooled spleen and draining LNs of wild-type and Gnmt ${ }^{-/}$ mice and stimulated with anti-CD3/CD28 monoclonal antibodies in the presence of Th1 or Th17 polarized conditions. Unexpectedly, our results indicated that the percentages of $\mathrm{CD}^{+} \mathrm{IFN}^{-} \gamma^{+}$(Figures 6A, B) and $\mathrm{CD}^{+} \mathrm{IL}^{-17 \mathrm{~A}^{+}}$(Figures 6C, D) cells were similar in these two groups, suggesting a dispensable role of GNMT in the differentiations of these two T-helper cell lineages. Since it has been reported that impairment of Treg cells increases the amounts of Th1 and Th17 cells and subsequently exacerbates the disease severity of EAE (33), we further analyzed the modulatory role of GNMT deficiency in Treg cell differentiation. Our results demonstrated that the percentage of polarized $\mathrm{CD}^{+}$FoxP3 $^{+} \mathrm{T}$ cells was markedly increased in $\mathrm{Gnmt}^{-/}$mice compared with that in wild-type mice (Figures $6 \mathrm{E}, \mathrm{F})$. These results suggested that GNMT deletion enhanced the differentiation of Treg cells, but not of Th1 and Th17 cells in vitro.

\section{GNMT Deficiency Increases the Amount of Treg Cells during EAE Development}

Since our results demonstrated that GNMT deficiency enhanced the differentiation of Treg cells in vitro (see Figures $6 \mathrm{E}, \mathrm{F}$ ), we further investigated the dynamic changes of Treg cells in $\mathrm{Gnmt}^{-/}$ mice at the initial and effector phases of EAE development. Our results indicated that the percentage of Treg cells was only slightly increased in Gnmt ${ }^{-/-}$mice at the initial phase (d 9 postimmunization) (Figures 7A, B) when compared with wild-type mice. Similar results also were observed in $\mathrm{Gnmt}^{-/-}$mice compared with wild-type mice at $\mathrm{d} 11$ postimmunization (Supplementary Figures 5A, B). Interestingly, at the effector phase (d 18 postimmunization), Gnmt ${ }^{-/-}$mice showed a significantly higher percentage of Treg cells than wild-type mice (Figures 7C, D), pro-

A
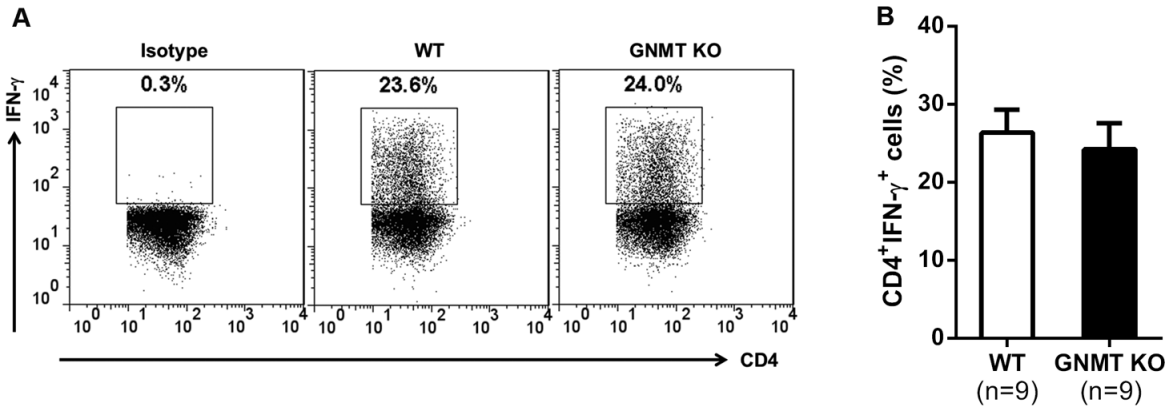

C

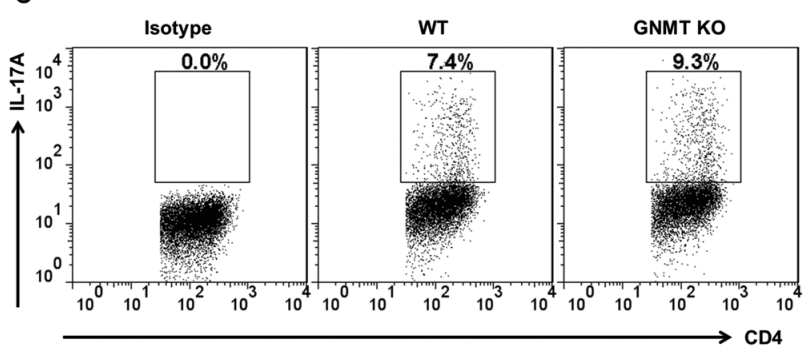

D

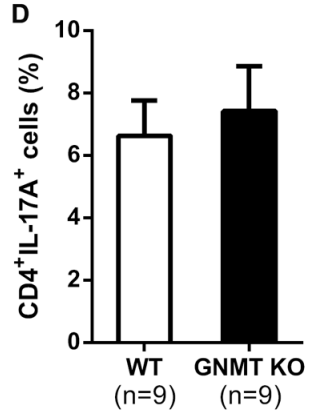

E

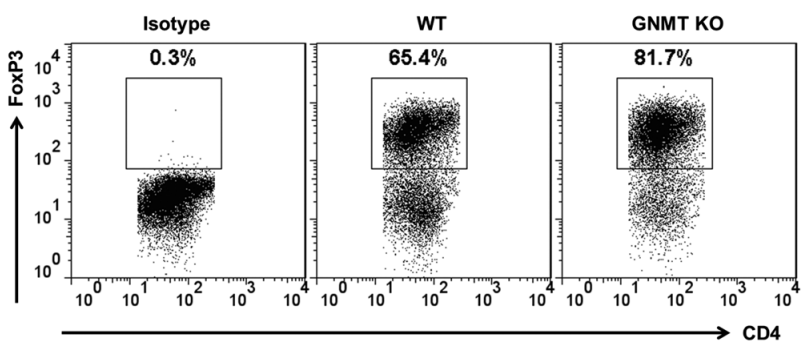

F

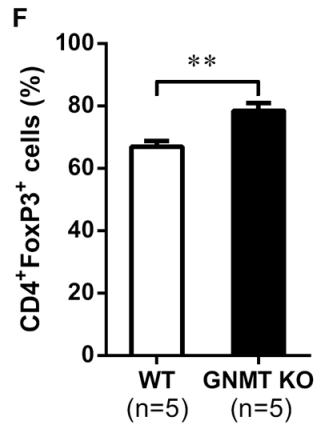

Figure 6. Effects of GNMT deficiency on $\mathrm{CD}^{+}{ }^{+}$T-cell differentiation in vitro. Purified $\mathrm{CD} 4^{+} \mathrm{CD} 25^{-}$ T cells from $\mathrm{Gnmt}^{-/-}$and wild-type mice were stimulated with anti-CD3/CD28 $(1 \mu \mathrm{g} / \mathrm{mL})$ in Th1, Th17 or in Treg polarized conditions for $3 \mathrm{~d}$. (A, C,E) Representative flow cytometric analysis and the histogram of percentage average of (B) CD4 $4^{+} \mathrm{IFN}-\gamma^{+}$, (D) CD4 $4^{+} \mathrm{IL} 17 \mathrm{~A}^{+}$ and (F) $\mathrm{CD}^{+}{ }^{+} \mathrm{Foxp}^{+} \mathrm{T}$ cells. All data are presented as mean \pm SEM. Statistics were calculated by the Student $t$ test. ${ }^{* *} p<0.01$.

viding a possible explanation for the amelioration of MOG-induced EAE in GNMT-deficient mice.

\section{GNMT Ablation Ameliorates Adoptive Transfer of EAE}

Since our results showed that GNMT deficiency significantly ameliorated EAE development (Figure 1) and markedly reduced the $\mathrm{CD} 4^{+} \mathrm{T}$-cell response (Figure 5), we further examined whether less susceptibility to EAE in $\mathrm{Gnmt}^{-/-}$mice was due to abnormal $\mathrm{Gnmt}^{-/-} \mathrm{CD} 4^{+} \mathrm{T}$-cell function. Lymphocytes were recovered from $9 \mathrm{~d}$ immunized wild-type and $\mathrm{Gnmt}^{-/}$mice and stimulated with $\mathrm{MOG}_{35-55}$ peptide for $96 \mathrm{~h}$. Then, wildtype and $\mathrm{Gnmt}^{-/-} \mathrm{CD}^{+} \mathrm{T}$ cells were purified (purity $>95 \%$ ) and transferred to wild-type recipient mice. Our results revealed that mice receiving MOG-reactive $\mathrm{CD}^{+} \mathrm{T}$ cells from $\mathrm{Gnmt}^{-/-}$mice exhibited amelioration of EAE development, characterized by a delayed onset of disease 
A

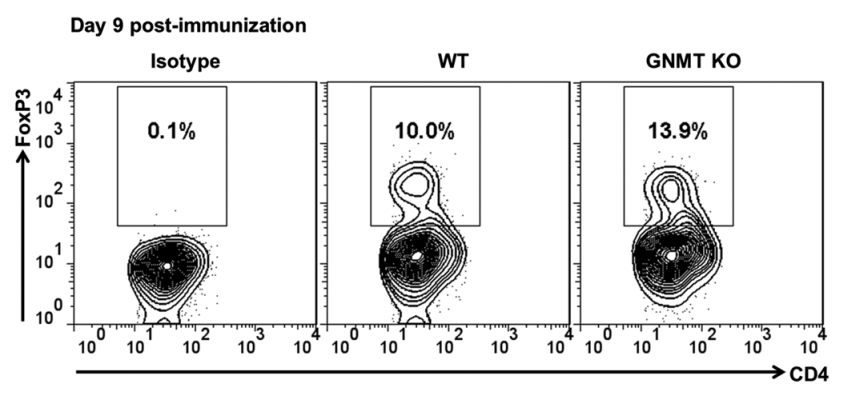

C

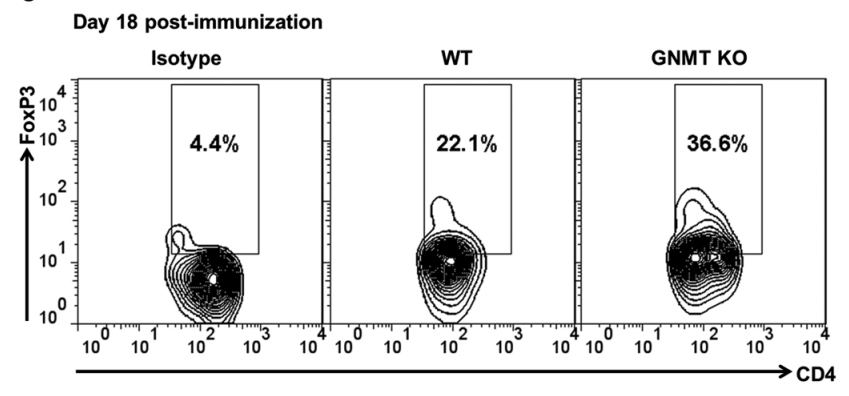

B

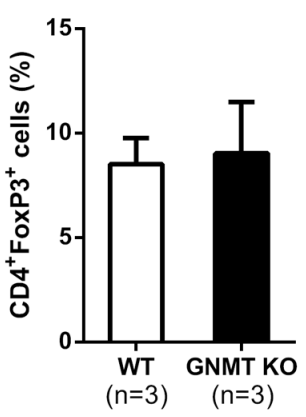

D

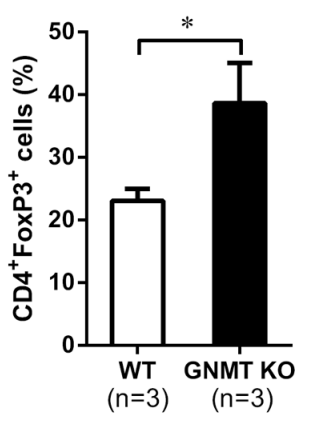

Figure 7. Ameliorated EAE in $\mathrm{Gnmt}^{-/-}$mice was associated with higher amount of Treg cells. Lymphocytes were recovered from draining LNs of 9-d (initial phase)- or 18-d (effector phase)-postimmunized mice and stimulated with PMA and ionomycin in the presence of monensin. The percentages of $\mathrm{CD}^{+} \mathrm{FoxP}^{+} \mathrm{T}$ cells were analyzed by flow cytometry. $(A, C)$ Representative flow cytometric analysis and $(B, D)$ the average percentages of $\mathrm{CD}^{+} \mathrm{FoxP}^{+} \mathrm{T}$ cells in $\mathrm{MOG}_{35-55^{-}}$-immunized wild-type and $\mathrm{Gnmt}^{-/-}$mice at $(\mathrm{A}, \mathrm{B})$ initial or $(C, D)$ effector phases. All data are presented as mean \pm SEM. Statistics were calculated by the Student $t$ test. ${ }^{*} p<0.05$.

$(\mathrm{KO}, 13 \pm 1.41 \mathrm{~d} ; \mathrm{WT}, 10.3 \pm 0.33 \mathrm{~d})$ and $\mathrm{a}$ slightly decreased mean maximal clinical score $(\mathrm{KO}, 3$; WT, 3.5) compared with control mice (Figures 8A, B).

We also purified $\mathrm{CD}^{+} \mathrm{T}$ cells from wild-type and $\mathrm{Gnmt}^{-/}$mice (purity $>95 \%$ ) and transferred them into Rag1-deficient recipient mice, which were subsequently immunized with $\mathrm{MOG}_{35-55} / \mathrm{CFA}$ one day later. Our results showed that the recipient mice receiving $\mathrm{Gnmt}^{-/-} \mathrm{CD}^{+} \mathrm{T}$ cells exhibited significant attenuation of EAE development, characterized by a slightly delayed onset of disease $(\mathrm{KO}, 12.3 \pm$ $1.15 \mathrm{~d}$; WT, $11 \mathrm{~d}$ ) and a decreased mean maximal clinical score $(\mathrm{KO}, 0.5 \pm 0.2 ; \mathrm{WT}$, $2.83 \pm 1.09)$ compared with mice receiving wild-type $\mathrm{CD}^{+} \mathrm{T}$ cells (Figures $8 \mathrm{C}, \mathrm{D}$ ). Collectively, these results suggested that amelioration of EAE in $\mathrm{Gnmt}^{-/-}$mice was associated, at least in part, with downregulation of $\mathrm{CD}^{+} \mathrm{T}$-cell function.

\section{DISCUSSION}

GNMT was first discovered in liver and plays an important role in the regulation of SAM/SAH ratio, liver detoxification pathway and signaling transduction (34). Previously, we generated and characterized a $\mathrm{Gnmt}^{-/-}$mouse model $(9,10)$. Since the $\mathrm{Gnmt}^{-/-}$mice developed HCC spontaneously, we proposed that GNMT is a HCC tumor suppressor gene (9). During the past decade, most functional studies of GNMT focused on the role of GNMT in the detoxification pathways, nutrition and tumorigenesis of HCC $(34,35)$. However, the role of GNMT in regulation of T-cell functions has never been defined. In this study, we showed that deficiency of GNMT significantly ameliorated the severity of EAE and decreased the responses of both MOG-specific Th1 and Th17 cells in the peripheral and central nervous system. In line with these findings, TCR stimulation-induced responses were attenuated in GNMT-deficient CD4 ${ }^{+} \mathrm{T}$ cells. Moreover, GNMT ablation markedly enhanced the differentiation of Treg cells. Collectively, our findings uncovered a novel role of GNMT in the regulation of $\mathrm{CD} 4^{+}$ T-cell function during EAE pathogenesis.

A potential role of GNMT in immune modulation has been investigated recently using several experimental models. For instance, atherosclerosis is a chronic inflammatory disease resulting from excessive lipid accumulation and a persistent chronic inflammatory process within the arterial wall (36). Using this model, we previously found that genetic deletion of GNMT in apolipoprotein E-deficient mice exacerbated the dysregulation of cholesterol efflux and inflammation in macrophages, thus leading to accelerated progression of atherosclerosis (11). In addition, Gomez-Santos et al. reported that functional loss of GNMT augmented NK cell-mediated inflammation and exacerbated endotoxin-induced acute liver injury (13). Moreover, absence of GNMT exacerbated the deregulation of the inflammatory response in an experimental ulcerative colitis model (12). Collectively, these evidences suggested that GNMT exerts protective antiinflammatory effects in acute inflammation models and during activation of innate immune responses. In contrast to the role of GNMT in innate immunity, in this study, our data showed that ablation of GNMT ameliorated EAE development and attenuated $\mathrm{CD} 4^{+} \mathrm{T}$-cell responses. Since EAE is a CD4 ${ }^{+}$T-cell-mediated inflammatory demyelinating disease of the CNS (26), GNMT may act as a proinflammatory agent during adaptive immune responses. Interestingly, such opposite roles of GNMT in innate and adaptive immune responses has been found in leptin (37). Nevertheless, how 
A

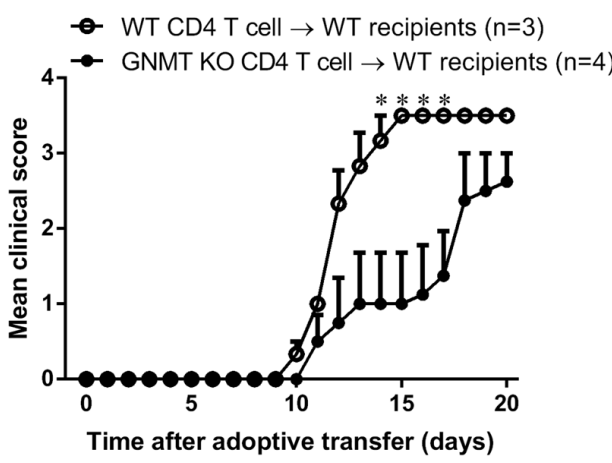

C

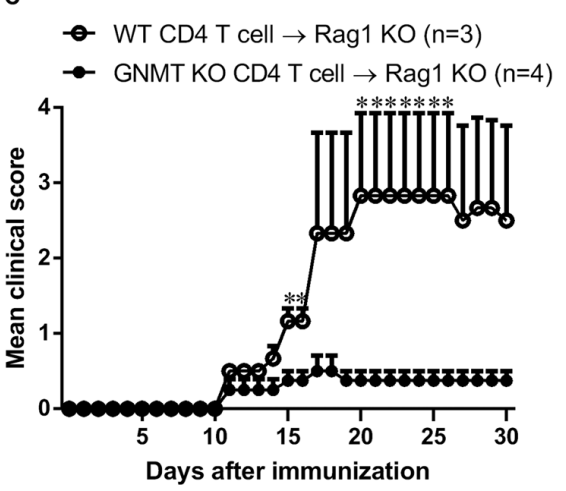

\begin{tabular}{|c|c|}
\hline & Incidence \\
\hline WT $\rightarrow$ WT recipient & $100 \%(3 / 3)$ \\
\hline GNMT KO $\rightarrow$ WT recipient & $100 \%(4 / 4)$ \\
\hline
\end{tabular}

D

\begin{tabular}{|c|c|}
\hline & Incidence \\
\hline WT $\rightarrow$ Rag1 KO & $100 \%(3 / 3)$ \\
\hline GNMT KO $\rightarrow$ Rag1 KO & $75 \%(3 / 4)$ \\
\hline
\end{tabular}

Figure 8. The efficiency of EAE induction of GNMT-deficient $C D 4^{+} T$ cells was lower than wild-type $\mathrm{CD}^{+} \mathrm{T}$ cells. (A and B) Wild-type and $\mathrm{Gnmt}^{-/-}$mice were immunized with $M G_{35-55}$ peptide/CFA. At d 9 postimmunization, mice were euthanized and total draining LN cells were further primed with $50 \mu \mathrm{g} / \mathrm{mL} \mathrm{MOG}_{35-55}$ peptide for $96 \mathrm{~h}$. Then, the CD4 ${ }^{+}$ T cells were purified (purity >95\%) and transferred to naive wild-type mice. (C and D) The $\mathrm{CD}^{+} \mathrm{T}$ cells (purity $>95 \%$ ) were isolated from wild-type and $\mathrm{Gnmt}^{-/-}$mice and injected

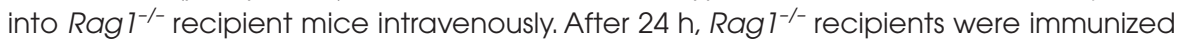
with $\mathrm{MOG}_{35-55}$ peptide/CFA to elicit EAE. Data are shown as mean \pm SEM for each group. Statistics were calculated by the Student $t$ test. ${ }^{*} p<0.05$.

GNMT fine tunes innate and adaptive immunity should be investigated further.

In this study, our results revealed that GNMT deficiency significantly ameliorated the severity of EAE and decreased inflammation and demyelination in the CNS. In addition, MOG-induced $\mathrm{Gnmt}^{-/}$ mice showed reduced MOG-specific T-cell proliferation and decreased induction of Th1 and Th17 cells, but had a higher amount of Treg cells. Moreover, the $\mathrm{CD}^{+} \mathrm{T}$ cells from $\mathrm{Gnmt}^{-/-}$mice showed lower TCR stimulation-induced responses than those from wild-type mice. Furthermore, the severity of adop- tive transferred EAE by GNMT-deficient $\mathrm{CD} 4^{+} \mathrm{T}$ cells was lower than that of wildtype $\mathrm{CD} 4^{+} \mathrm{T}$ cells. Collectively, our findings suggested that impaired development of EAE in $\mathrm{Gnmt}^{-/-}$mice occurred, at least in part, through modulation of $\mathrm{CD} 4^{+}$ T-cell function. However, we failed to completely exclude the possibility that the effects of GNMT deficiency in other cell types could also account for impaired EAE development in $\mathrm{Gnmt}^{-/-}$mice. This still needs to be investigated further.

In addition to the aforementioned mechanism, the effects of GNMT deficiency in one carbon metabolism may also contribute to decreased EAE devel- opment. The major players in the transmethylation pathway include methyltransferase-mediated donation of methyl groups by SAM and conversion of SAM to SAH, which can act as a potent feedback inhibitor of methyltransferase (38). This reaction is tightly controlled by $S$-adenosylhomocysteine hydrolase (SAHase), a highly conserved ubiquitous enzyme that hydrolyzes SAH into adenosine and homocysteine (39). It is reported that SAHase inhibitors not only inhibit SAHase but also result in the accumulation of SAH and SAM $(40,41)$. Interestingly, a range of studies found that inhibition of transmethylation by using SAHase inhibitor curtailed the effector function of $\mathrm{CD} 4^{+}$ $\mathrm{T}$ cells and EAE development $(42,43)$. Moreover, inhibition of methyl transfer enzymes results in a less compact myelin in oligodendroglial cells, and the methylation status of myelin basic protein (MBP)-arginine is associated with stability of myelin structure $(44,45)$. Intriguingly, our $\mathrm{Gnmt}^{-/-}$mice showed an increased level of hepatic SAM, reduced expression of Ahcy (10) and global DNA hypomethylation (4), suggesting that one carbon metabolism may provide another explanation for impaired EAE in $\mathrm{Gnmt}^{-/-}$mice. Further studies are required to elucidate these mechanisms.

It was reported previously that the engagement of TCR and costimulatory receptor-CD28 increases the expression level of CD25 and the amount of IL-2 secretion and then initiates an IL-2-driven proliferation of $\mathrm{CD}^{+} \mathrm{T}$ cells (46). In this study, we showed that deficiency of GNMT significantly attenuated TCR stimulation-induced $\mathrm{CD} 4^{+} \mathrm{T}$-cell proliferation, but had no discernible roles in induction of CD25 and IL-2 production, suggesting that GNMT-deficient $\mathrm{CD}^{+}$ $T$ cells had potentially equivalent IL-2R signaling compared with wild-type $\mathrm{T}$ cells. This phenomenon resembles the findings in $\mathrm{mTOR}^{-/}$and T-Rheb ${ }^{-/}$mouse models. T cells lacking mTOR or Rheb expression did not demonstrate a block in proliferation, but instead proliferated more slowly than their wild-type coun- 
terparts $(47,48)$. In addition, a previous study reported that prolonged engagement of TCR and CD28 bypasses the requirement of IL-2 and sustains IL-2independent T-cell proliferation through mTOR signaling (49). Furthermore, mTOR recently has been shown to promote naïve $\mathrm{CD}^{+}{ }^{+} \mathrm{T}$-cell proliferation through degradation of GRAIL (30). Interestingly, our previous study showed GNMT was able to activate mTORC1 downstream signaling by interrupting the interaction between mTOR and DEPTOR (5). Consistent with previous studies, our results revealed that GNMT deficiency impaired TCR stimulation-induced mTOR signaling and thus maintained high levels of GRAIL expression in stimulated $\mathrm{CD}^{+} \mathrm{T}$ cells. Collectively, our results indicated that GNMT deficiency attenuated TCR-stimulated CD4 ${ }^{+}$T-cell proliferation by decreasing the mTOR signaling pathway mediated GRAIL degradation in an IL-2-independent manner.

\section{CONCLUSION}

In summary, this study portraits a novel role of GNMT in EAE pathogenesis, TCR stimulation-mediated $\mathrm{CD} 4^{+}$ $\mathrm{T}$-cell responses and $\mathrm{CD} 4^{+} \mathrm{T}$-cell differentiation. In addition, an underlying molecular mechanism of GNMT in the mTOR signaling pathway to modulate $\mathrm{CD} 4^{+} \mathrm{T}$-cell proliferation has been described further. Our novel findings are valuable for the development of GNMTbased therapeutic strategies for the treatment of multiple sclerosis.

\section{ACKNOWLEDGMENTS}

This study was supported partially by Kaohsiung Medical University Aim for the Top Universities Grant, KMU-TP103E00 and KMU-TP103E09; Aim for the Top 500 Universities Grant, DT103009; NSYSUKMU JOINT RESEARCH PROJECT, NSYSUKMU103-I010; Progam to Upgrade the R\&D Capabilities of Private Universities Grant, MOST103-2632-B-037-001; and Health and Welfare Surcharge of Tobacco Products, Ministry of Health and Welfare Grant, MOHW103-TD-B-111-05. We thank
Chuen-Miin Leu for providing reagents, Marcelo Chen for revising the English writing and the staff from the Center of Infectious Disease and Cancer Research (CICAR) of Kaohsiung Medical University for technical assistance.

\section{DISCLOSURE}

Parts of the results have been reported at the 2012 Cold Spring Harbor Asia Conferences-Frontiers of Immunology in Health and Diseases.

\section{REFERENCES}

1. Ogawa H, Fujioka M. (1982) Purification and properties of glycine N-methyltransferase from rat liver. J. Biol. Chem. 257:3447-52.

2. Cook RJ, Wagner C. (1984) Glycine N-methyltransferase is a folate binding protein of rat liver cytosol. Proc. Natl. Acad. Sci. U. S. A. 81:3631-4.

3. Chen SY, et al. (2004) Glycine N-methyltransferase tumor susceptibility gene in the benzo(a)pyrenedetoxification pathway. Cancer Res. 64:3617-23.

4. Yen CH, et al. (2009) Glycine N-methyltransferase affects the metabolism of aflatoxin B1 and blocks its carcinogenic effect. Toxicol. Appl. Pharmacol. 235:296-304.

5. Yen $\mathrm{CH}$, et al. (2012) Functional characterization of glycine N-methyltransferase and its interactive protein DEPDC6/DEPTOR in hepatocellular carcinoma. Mol. Med. 18:286-96.

6. Liao YJ, et al. (2012) Glycine N-methyltransferase deficiency affects Niemann-Pick type C2 protein stability and regulates hepatic cholesterol homeostasis. Mol. Med. 18:412-22.

7. Chen YM, et al. (1998) Characterization of glycine$\mathrm{N}$-methyltransferase-gene expression in human hepatocellular carcinoma. Int. J. Cancer. 75:787-93.

8. Liu HH, et al. (2003) Characterization of reduced expression of glycine N-methyltransferase in cancerous hepatic tissues using two newly developed monoclonal antibodies. J. Biomed. Sci. 10:87-97.

9. Liao YJ, et al. (2009) Characterization of a glycine $\mathrm{N}$-methyltransferase gene knockout mouse model for hepatocellular carcinoma: Implications of the gender disparity in liver cancer susceptibility. Int. J. Cancer. 124:816-26.

10. Liu SP, et al. (2007) Glycine N-methyltransferase-/mice develop chronic hepatitis and glycogen storage disease in the liver. Hepatology. 46:1413-25.

11. Chen CY, et al. (2012) Deficiency of glycine $\mathrm{N}$-methyltransferase aggravates atherosclerosis in apolipoprotein E-null mice. Mol. Med. 18:744-52.

12. Chou WY, et al. (2014) Role of glycine N-methyltransferase in experimental ulcerative colitis. J. Gastroenterol. Hepatol. 29:494-501.

13. Gomez-Santos L, et al. (2012) Inhibition of natural killer cells protects the liver against acute injury in the absence of glycine N-methyltransferase. Hepatology. 56:747-59.
14. McFarland HF, Martin R. (2007) Multiple sclerosis: a complicated picture of autoimmunity. Nat. Immunol. 8:913-9.

15. Bottiglieri T, Hyland K, Reynolds EH. (1994) The clinical potential of ademetionine (S-adenosylmethionine) in neurological disorders. Drugs. 48:137-52.

16. Hyland K, et al. (1988) Demyelination and decreased S-adenosylmethionine in 5,10-methylenetetrahydrofolate reductase deficiency. Neurol ogy. 38:459-62.

17. Metz J. (1992) Cobalamin deficiency and the pathogenesis of nervous system disease. Annu. Rev. Nutr. 12:59-79.

18. Friese MA, Jensen LT, Willcox N, Fugger L. (2006) Humanized mouse models for organspecific autoimmune diseases. Curr. Opin. Immunol. 18:704-9.

19. Bettelli E, et al. (2004) Loss of T-bet, but not STAT1, prevents the development of experimental autoimmune encephalomyelitis. J. Exp. Med. 200:79-87.

20. Ivanov, II, et al. (2006) The orphan nuclear receptor RORgammat directs the differentiation program of proinflammatory IL-17+ T helper cells. Cell. 126:1121-33.

21. Murphy AC, Lalor SJ, Lynch MA, Mills KH. (2010) Infiltration of Th1 and Th17 cells and activation of microglia in the CNS during the course of experimental autoimmune encephalomyelitis. Brain Behav. Immun. 24:641-51.

22. Stromnes IM, Goverman JM. (2006) Active induction of experimental allergic encephalomyelitis. Nat. Protoc. 1:1810-9.

23. Li H, Nourbakhsh B, Ciric B, Zhang GX, Rostami A. (2010) Neutralization of IL-9 ameliorates experimental autoimmune encephalomyelitis by decreasing the effector $\mathrm{T}$ cell population. J. Immunol. 185:4095-100.

24. Lin MH, et al. (2014) T cell-specific BLIMP-1 deficiency exacerbates experimental autoimmune encephalomyelitis in nonobese diabetic mice by increasing Th1 and Th17 cells. Clin. Immunol. 151:101-13.

25. El-behi M, Rostami A, Ciric B. (2010) Current views on the roles of Th1 and Th17 cells in experimental autoimmune encephalomyelitis. J. Neuroimmune. Pharmacol. 5:189-97.

26. Kuchroo VK, et al. (2002) T cell response in experimental autoimmune encephalomyelitis (EAE): role of self and cross-reactive antigens in shaping, tuning, and regulating the autopathogenic T cell repertoire. Annu. Rev. Immunol. 20:101-23.

27. Bonnevier JL, Yarke CA, Mueller DL. (2006) Sustained B7/CD28 interactions and resultant phosphatidylinositol 3-kinase activity maintain G1-->S phase transitions at an optimal rate. Eur. J. Immunol. 36:1583-97.

28. Lucas PJ, Negishi I, Nakayama K, Fields LE, Loh DY. (1995) Naive CD28-deficient T cells can initiate but not sustain an in vitro antigen-specific immune response. J. Immunol. 154:5757-68. 
29. Powell JD, Ragheb JA, Kitagawa-Sakakida S, Schwartz RH. (1998) Molecular regulation of interleukin-2 expression by CD28 co-stimulation and anergy. Immunol. Rev. 165:287-300.

30. Lin JT, et al. (2009) Naive CD4 T cell proliferation is controlled by mammalian target of rapamycin regulation of GRAIL expression. J. Immunol. 182:5919-28.

31. Jones RG, Thompson CB. (2007) Revving the engine: signal transduction fuels $\mathrm{T}$ cell activation. Immunity. 27:173-8.

32. Mondino A, Mueller DL. (2007) mTOR at the crossroads of $\mathrm{T}$ cell proliferation and tolerance. Semin. Immunol. 19:162-72.

33. Kumar V, Stellrecht K, Sercarz E. (1996) Inactivation of $\mathrm{T}$ cell receptor peptide-specific $\mathrm{CD} 4$ regulatory $\mathrm{T}$ cells induces chronic experimental autoimmune encephalomyelitis (EAE). J. Exp. Med. 184:1609-17.

34. Yen CH, Lin YT, Chen HL, Chen SY, Chen YM. (2013) The multi-functional roles of GNMT in toxicology and cancer. Toxicol. Appl. Pharmacol. 266:67-75.

35. Wang YC, Tang FY, Chen SY, Chen YM, Chiang EP. (2011) Glycine-N methyltransferase expression in HepG2 cells is involved in methyl group homeostasis by regulating transmethylation kinetics and DNA methylation. J. Nutr. 141:777-82.

36. Glass CK, Witztum JL. (2001) Atherosclerosis. the road ahead. Cell. 104:503-16.

37. Bernotiene E, Palmer G, Gabay C. (2006) The role of leptin in innate and adaptive immune responses. Arthritis Res. Ther. 8:217.

38. Yuan CS, Saso Y, Lazarides E, Borchardt RT, Robins MJ. (1999) Recent advances in S-adenosylL-homocysteine hydrolase inhibitors and their potential clinical applications. Expert Opin. Ther. Pat. 9:1197-206.

39. De La Haba G, Cantoni GL. (1959) The enzymatic synthesis of S-adenosyl-L-homocysteine from adenosine and homocysteine. J. Biol. Chem. 234:603-8.

40. Wu QL, et al. (2005) Inhibition of S-adenosyl-Lhomocysteine hydrolase induces immunosuppression. J. Pharmacol. Exp. Ther. 313:705-11.

41. Jurgensen $\mathrm{CH}$, Wolberg G, Zimmerman TP. (1989) Inhibition of neutrophil adherence to endothelial cells by 3-deazaadenosine. Agents Actions. 27:398-400.

42. Lawson BR, et al. (2007) Inhibition of transmethylation down-regulates $\mathrm{CD} 4 \mathrm{~T}$ cell activation and curtails development of autoimmunity in a model system. J. Immunol. 178:5366-74.

43. Fu YF, et al. (2006) A reversible S-adenosyl-Lhomocysteine hydrolase inhibitor ameliorates experimental autoimmune encephalomyelitis by inhibiting T cell activation. J. Pharmacol. Exp. Ther. 319:799-808.

44. Dinn JJ, et al. (1980) Methyl group deficiency in nerve tissue: a hypothesis to explain the lesion of subacute combined degeneration. Ir. J. Med. Sci. $149: 1-4$

45. Kim S, Lim IK, Park GH, Paik WK. (1997) Biologi- cal methylation of myelin basic protein: enzymology and biological significance. Int. J. Biochem. Cell Biol. 29:743-51.

46. Smith-Garvin JE, Koretzky GA, Jordan MS. (2009) T cell activation. Annu. Rev. Immunol. 27:591-619.

47. Delgoffe GM, et al. (2009) The mTOR kinase differentially regulates effector and regulatory $\mathrm{T}$ cell lineage commitment. Immunity. 30:832-44.

48. Delgoffe GM, et al. (2011) The kinase mTOR regulates the differentiation of helper $\mathrm{T}$ cells through the selective activation of signaling by mTORC1 and mTORC2. Nat. Immunol. 12:295-303.

49. Colombetti S, Basso V, Mueller DL, Mondino A. (2006) Prolonged TCR/CD28 engagement drives IL-2-independent T cell clonal expansion through signaling mediated by the mammalian target of rapamycin. J. Immunol. 176:2730-8. 